\title{
Entering the Classroom of the University in North America: Feelings on Academic Visiting \& Thoughts on Teaching
}

\author{
Lin-lin XIA \\ School of Automation Engineering, Northeast Dianli University, Jilin, China
}

\begin{abstract}
The lively lecture in Harvard University initiates the author's thoughts and consideration associated with the education issues during the academic visiting in North America. From my views of prospective, the deficiency of reading amount seriously affected the teaching quality and degree programs for the domestic graduate education, which then can hardly inspire the potentials of the students. Specifically, the respective roles of the teachers, the supervisors and the graduate students themselves in studies are taken into account in this paper, and the main causes of such problem are analyzed. Finally, the measures and resources are stated improving the teaching forms, enhancing the accumulation of academic and creating the academic atmospheres.
\end{abstract}

KEYWORD: Reading Amount; Teaching Quality; Degree Program; Potential Inspiration; Feelings on Academic Visiting

\section{FEELING LIVELY LEARNING ATMOSPHERE IN HARVARD CLASSROOM}

During my academic visiting stay overseas, I unexpectedly have the honor to attend a sociology lecture for graduate students in Harvard University. The topic discussed was related to the labor markets of the society today, and the society issues were further interpreted from the career choice \& payment situation under different sexual and racial visions. The young lady lecturer started the lesson from a very stuff of a movie, getting the students into the topics gradually. The movie selected here is 'Modern Times', a classic work form Charles Chaplin. Just as we all know, under the background of the Great Depression of states, the working class suffered from the capitalist exploitation oppression, and the copy presented us a portrait describing the hard circumstances of millions of the unemployed.

The lady lecturer chose several scenes of the copy:1) The titular character Charles made the repeated hand nut and got caught in and out in the machine. 2) Charles had to punch card, if he wanna go to the restroom, and he fled away nervously after he got caught by the boss when he was smoking for a rest. 3) Charles suffered from the mental disorders, he chased the people passing by, and he even wanted to tighten the nut on the noses or buttons of passersby. Obviously, all these vivid scenes were hilarious ones, and the students at present laughed at times as the movie went on. Whereas, this kind of ironic stories finally set the students thinking, and the classroom got quiet slowly, a question brought out in their deep heart: It is the constantly accelerated speed for the assembly line increased the distortion of the human character, right?

The scene then switched after finishing ten minutes' show, the lady lecturer analyzed the labor markets under the background of the mechanized large-scale production of states, the working and living circumstances of the working class, and together with the heavy physical and mental pressures the workers were suffering. Times and era moved on subsequently, the sexual and racial career distribution related to major career groups were elaborately stated since the last1980s, and the topics were associated with the male to the female/the black to the white ratio among the employers engaged in the administrative, the retail business and the service industries separately. Furthermore, the annual average paying ranking between, respectively, the white male and the white female, the Asian male and the Asian female, the African male and the African female were given, and the living status and social division of labor of the states were described accordingly.

Just as the other strain courses of the Harvard Universities, the lecture here was full of key information, and the lady's speed was extremely fast. In the last 15 minutes, the teacher and students 
discussed the book ' The Boy Kings: A Journey into the Heart of the Social Network' by Kathering Rosse. The author recorded her personal experience as the earliest fifty-first employees at Facebook using an autobiographical style. Moreover, the author also recorded the growth of Facebook in her book with a background of fast development of Internet. What's more, the book is related to the social, female vocational field and enterprise culture, which fit the aims of the course quite well.

In the interactive discussion process, the lady lecturer firstly asked the students at present whether they have read this book totally. Some of the students responded by handing up. The teacher looked around fast as a response, and then, she talked about the certain parts which she concerned and loved mostly. Besides, she stated her personal views. The lady picked up some social issues in the book and invited the students to participate in the discussion and her questions were quite progressive correspondingly. The students presented their own understanding, and the teacher showed her commend. Eventually, the lady lecturer mentioned the enlightenment about the different sexual, racial class of labor market situation in the book. In my point of view, it is quite appropriate to introduce the topics about the remuneration and social life from a gender and race perspective in such a lecture. After all, Facebook itself and Zuckerberg himself is very popular. For the author, her female identity, professional, and occupation resume in facebook are also extremely intriguing. As a non - technical and non-capital, but professional female staff, Katherine Rosse was far away from the subject company male engineers. With the efforts, she joined her favorite Engineering Department and became a blog ghostwriter, all these proved that she is also valuable as an non-technical staff in 'hacker worship' company.

If there were not enough contents read by the students, it is difficult for them to participate in the final discussion of last 15 minutes. There would be no ideological collisions between students and teachers since no interaction existed. However, it must be admitted that what we lost is not only the last 15 minutes. All these pushed me to be deep in thoughts, viz., the reading amount for the graduates education.

\section{MY PERSPECTIVE-RELATIONSHIP BETWEEN READING \& TEACHING QUALITY}

There is a common phenomenon that the amount of extracurricular reading is vastly huge in the education system of North America, most professors will cite a lot in their lectures. The teachers also assigned work associated with a lot of newspapers, magazines, books and other materials and required students to read after class. A Harvard girl who graduates from Peking University also said: "For me, the reading amount here in a week is equal to that in a year when I was in Beijing." In such an education system, adequate preparation before lecture is an unreasonable must. It takes a lot of time on retrieving data, reading, and analysis cases, sometimes it would even take several days for the survey in street. Accordingly, this makes students learn to comprehend correctly and think about why knowledge is so-called a kind of knowledge and why knowledge is so-called a kind of wisdom.

I deeply felt that lacking of reading amount is a common phenomenon in Chinese education system. I will set up an example coming from my own teaching experience for graduates to show this. When I was teaching uncertain reasoning part of lecture "Artificial Intelligence", we encountered a term Fuzzy Logic, which is a transformation concept from symbolic intelligence to computational one [1]. Obviously, the knowledge itself is quite important in the course. Therefore, I kept updating the content, information and references during the class, 'cause I wanted to share the adequate materials with students. Among them, a paper with the title "Fuzzy system: Challenges and chance - My Experiences and Perspectives' by Wang Li-xin (a famous scholar in Fuzzy Logic area,) in Acta Automatica Sinica, is pretty good. The author elaborated the disputes, challenges and opportunities in fuzzy learning by his own experiences and many technical problems are highly summarized [2]. Therefore, I strongly recommend that students should read it after class and I uploaded the paper in pdf format to the course mailbox in time. But a few days later, when I mentioned several parts of this paper, no one could response me and no interactive scenes turned up as expected, I got fully disappointed. On one hand, our students show less concern on the courses selected and ignore the reading process, depending only upon the direct interpretations form teachers. Also, they do not know the importance of listening. Sometimes, after 40 credit hours of a course, they don't even know the subject matter. On the other hand, lacking of reading amount makes it hard for the teacher to further the course with appropriate speed, nor expand the relevant cutting-edge knowledge in class.

\section{MY PERSPECTIVE-RELATIONSHIP BETWEEN READING \& DEGREE PROGRAMS}

Without a strong sense of reading also largely limits the exploration of new methods. If students have not experienced a large amount of scientific literature reading, suspicion, analysis and reasoning process, they will definitely have no idea about the value, 
advantages \& limitations, and development direction of the undergoing subjects. In general, chapter 1 of the dissertation will be associated with the research status of this area. Up to now, the author have reviewed and defended more than 100 papers, whereas, honestly speaking, there are some but rare wonderful ones among them. When we explore the reasons, first one would be the reading amount. Students trend to only read the literature assigned by tutors so as to fulfill the specific targets. And the truth is they are usually not sure about the meaning of the subject matter and don't know the outstanding contributions and value of the papers from other scholars. Actually, the author firmly believes that, the students should grasp the following key points: the scholars' interests of the same fields (tracking of foreign development situation and reading sufficient foreign journals), the advantages \& limitations of methods currently employed, the specific application fields, the problems addressed by the method adopted, and the features \& innovations of the corresponding solutions, etc. In fact, all these clearly show the theoretical significance and practical value of the paper, which is just what we try to express. Admittedly, plenty of reading and deep thinking constitute the premise for this, meanwhile, the writing itself is a kind of output of knowledge, and the essential part before is the input of knowledge, reading has impact on these two forms.

\section{REFERENCE FOREIGN EDUCATION PATTERN AND INSPIRE STUDENTS' POTENTIAL}

There is no denying that lacking of reading amount has greatly influenced the quality of graduate education in universities, causing serious "vicious cycle" phenomenon. As for the reasons, first, the guidance and emphasis 'degree' about reading amount from teachers is not enough. Second, refer to cultivation of the students, the supervisors pay more attention to the scientific research project rather than the basic reading. Third, the students themselves show less concentration on the subject matter. When it comes to the issues of specific improvement measures, the author insists that by referring the foreign education forms, we should base on the basic education and guide the students' innovation consciousness to inspire their potentials. Targeting at three reasons mentioned above, I would like to put forward some countermeasures.

\subsection{Improve the teaching form and increase mark ratio of seminars}

In China, more attentions have been given to the lecturers' teaching link, ignoring the students' characters in class. How can the students benefit from their participating in the course? With reference of foreign teaching mode (majority schools are equipped with seminar rooms, students there can be seated around or in groups), more seminar segments could be added to courses, and the students' performances here can be highly included in the final exam. Moreover, for the homework, parts of it can also be involved in class in form of a seminar, replacing the traditional form of written materials. It is noteworthy that each group should have a clear division of labor, and each student has his or her personal responsibility. As for the subjects, both teachers and students should discuss them in advance. And the students need to do a large number of data retrieval, sorting and reading, refining results, and sometimes they also need to do some mathematical modeling and computer simulation after class. In the class, each group takes turns to express the opinions, answering questions from the teachers and inquiries from the other groups. Through this process, the group can be aware of the directions of improvement. In addition, students are allowed to do some free discussions on certain themes during discussing process. As for the functions of the teachers, they evaluate and mark each group's assignments, and definitely present their evaluation of each student according to their performances within the group. Note also that, the weight of the seminar in the total score varies according to the nature of the course, I personally think it should be no less than $30 \%$. By this means, every student is encouraged to develop the habit of reading, fully cultivating the consciousness of participation and cooperation.

\subsection{Enhance academic accumulation, sturdy capacity building for scientific research}

Differing from basic capacity building in undergraduate stage, graduate students are influenced by their supervisors and are generally involved in research project within the supervisors' directions. At the same time, the supervisors tend to pay more attentions to enhance student's research capacity. Regardless the topic is chosen or not, intensive reading is the most effective and fast way to enlighten students to create their own opinions. Here, I would like to emphasize the word of "sturdy", guaranteeing that the supervisors will not make the students to take part in the projects too early or too much, fully ranking the importance of elementary reading. We always learn that during student's dissertation presentation that, they were sent to mills and enterprises at the beginning of master course to do filed survey, which, indeed, collected many valuable data. Unfortunately, from their dissertations we found that those are more like lab reports, they did lots of work, but the dissertations were lack of enough analyses on 
relevant theories. With rough processing of data and mediocre methods, lack of theoretical analyses of lab test or simulation results, their dissertations usually appear to have poor readability. To be honest, lacking of basic capacity building is just the reason, some suggestions and measures on reading literature and academic accumulation are given here:1) closely following research institutions' website related to their research area, download papers published by specialists, product reference guide, product data sheet, user manual and on-line technical support etc. 2) Carefully study literature database, according to my personal experience, for engineering students, the articles cited by SCI are generally prominent of innovative. Students should pay more attentions to Wiley Blackwell, Elsevier science, INSPEC, IEEE Library and so on. Besides, other related literature will also provide common ideas and methods, thus, keeping an eye on other cited science literature database is suggested as well. 3) Learn to look up references used by articles, in other words, trace its original sources. Especially for review articles, the author usually has already conducted wide reading, come up with the summaries and discussions, and further pointed out the development directions in the future, so looking for the references of a literature is the way to get the most authoritative, and the very sources of thought; 4) According to our needs, decision need to be made if extensive reading or intensive reading of an article is required, abstract of each article should always require intensive reading. For intensive reading of the whole article, take notes and tags is also very critical, it reminds you what the optimal research method and experimental method is feasible, over times, you will be able to objectively evaluate the advantages and disadvantages, applicable scope, or limitations of methods, and you are capable of finding the best strategies for your own subject.

\subsection{Create studying atmosphere and improve study efficiency}

You will probably often hear that the students are facing confusions ----they think they have plenty of time, and, of course, lots things to study, but they don't know where to start and how to do. It is not so hard to understand it, when they were undergraduates they were under the pressures to complete courses credits, and they spent almost all the time attending classes and exams. While, now the concept of class and course loses its importance, the laboratory and project and supervisor's guidance on a general research direction are the keys instead, and the students should explore details themselves. This kind of freedom and loosened environment is always more difficult for those who have no selfmanage abilities. As the subject goes on, if you lack necessary basic capacity training, and you want to relearn (for engineering students, the capacity of computer programming is a must, Matlab and Visual $\mathrm{c}++$, Labview are commonly used tool), you are wasting time. How to make a start, and build up academic accumulation skills? I personally believe setting a short-term and long-term target is a good way to create a learning atmosphere, realizing self regulating. For the short-term target, setting a fixed timing for completing several literature reading, using numerical simulation to code an algorithm, etc. For the long-term target, completing which part (hardware or software) of the project, or finding out technology method or the innovation points of a subject, for example, at end of one semester. Indeed, reading is the process of input, but you would also think, obtain and criticize when you are reading, so reading itself is the circulation of suspect and affirmation. Overall, one hour's effective reading is better than staring at screen of computer all the day, because this pattern brings valuable output and greatly improves the study efficiency.

\section{CONCLUDING REMARKS}

The postgraduate research guides people to get into a precious learning time, in which one can be capable of develop his or her own independent scientific research ability. Chasing a such kind of degree, people would like to learn how to read, how to think, and how to discover. When we enter the classrooms of North America, it is shown that the academic accomplishments and expressions of Asian students are second to none compared with any student of the other countries, specifically, Chinese students are efficient enough, and they can achieve remarkable success as well, even if they are now in different kinds of society systems. By contrast, the domestic postgraduate education are definitely lacking of the important parts associated with inspiring the students' potential. It is appreciate that, however, the potential means endless possibilities, the imagination beyond one's horizon, and the more significant achievements in the near future. I sincerely hope that students who are doing their master degrees are no longer confused when facing the research work, and also the career choice.

\section{REFERENCES}

[1] Wang Li-xin. Reply: Some Thoughts on Fuzzy Thinking. Acta Automatica Sinica, 2002, 28 (4) :670-672.

[2] Wang Li-xin. Fuzzy Systems: Challenges and Chance-My Experiences and Perspectives. Acta Automatica Sinica, 2001, 27 (4) : 585-590. 